\title{
Importance of emotional regulation in obesity and weight loss treatment
}

\author{
Isabel Silva \\ Universidade Fernando Pessoa, Porto, Portugal
}

\begin{abstract}
This theoretical study discusses the importance of emotional regulation process in obesity and in the success/failure of weight loss treatment, systematizing results of empirical studies and theoretical developments that have occurred in this field. Although there has been a substantial interest about this theme, it is difficult to achieve a consensual formulation to explain the relation between emotional regulation and weight because of the huge variability in the methodologies adopted and of the complexity of this phenomenon. In spite of all efforts, more than definite answers, studies have been revealing new research paths to be followed in this complex field.
\end{abstract}

Keywords: emotion; regulation; mood; obesity; eating.

\section{Importância da regulação emocional na obesidade e tratamento para emagrecer ${ }^{\star}$}

\begin{abstract}
Resumo
Este estudo teórico discute a importância do processo de regulação emocional na obesidade e no sucesso/fracasso do tratamento para a perda de peso, sistematizando resultados de estudos empíricos e desenvolvimentos teóricos que ocorreram neste campo. Embora tenha havido um interesse substancial sobre este tema, é dificil alcançar uma formulação consensual para explicar a relação entre a regulação emocional e o peso por causa da enorme variabilidade das metodologias adotadas e da complexidade do fenômeno. Apesar de todos os esforços, mais do que respostas definitivas, os estudos têm revelado novos caminhos de pesquisa a ser seguido neste campo complexo.
\end{abstract}

Palavras-chave: emoção; regulação; humor; obesidade; ingestão.

\section{Introduction}

Although there has been an interest about the role of mood, emotions, and emotional regulation process in obesity for long time, the exact process by which emotions affect eating behaviour continuous an unanswered question.

In this paper, we propose to consider the role of mood, emotions and emotional regulation on food intake and in treatments for weight loss.

\section{Obesity, mood and emotional disorders}

Research is relatively consensual in considering that overweighed individuals and people with obesity are at particular risk of developing depressive mood (MERWE, 2007; SIMON et al., 2006) and anxiety disorders (BECKER et al., 2001; SIMON et al., 2006), which is, in its turn, a factor that may contribute to weight regain in patients integrated in weight-loss treatments.

A nationwide study, conducted by Kark, Neovius and Rasmussen (2010), with Swedish men, which aimed to analyze if there is an association between underweight, overweight and obesity in young adult men and disability pension risk due to psychiatric disorders revealed that underweight and overweight men were associated with small risk increases, whereas higher risks for disability pension of this type were generally found for obesity.

\footnotetext{
^Endereço para correspondência: Universidade Fernando Pessoa - Faculdade de Ciências Humanas e Sociais - Departamento de Ciência Política e do Comportamento. Praça 9 de Abril, 349 - Porto. 4249-004 Porto, Portugal. E-mail: isabels@ufp.edu.pt

$\star \star O$ presente trabalho não recebeu financiamento, nem qualquer apoio técnico
}

Klinitzke et al. (2013, p. 277) performed a systematic literature review on the relationship between obesity and suicide risk in adults in an attempt to understand what they call an "ambiguous research field". Eight of the epidemiological and ecological studies analyzed revealed a negative association between obesity and completed suicide - i.e. obese patients are less likely to commit suicide than individuals with low or normal weight; one of the studies concluded that there is no association between weight and committing suicide; and another showed a positive association between these two variables. Distinct results were found when suicide attempts and suicidal ideation were considered, revealing that obese women reported more suicide attempts and suicidal ideation, while men showed less attempts and less suicidal thoughts.

In the same year, Zhang, Li, and McKeown (2013) also conducted a critical review of the epidemiological evidence on the association between body mass index and suicidal behaviours, in an attempt to understand the inconsistencies found in previous studies. These authors found that almost all cohort studies revealed an inverse association between body mass index and the risk of completed suicide (regardless origin region and gender of the individuals). And, similarly, found that, among men, a high body mass index was associated to lower risk of attempted or completed suicide, while, in women, a high body mass index was associated with higher risk of suicidal attempts, but with lower risk of completed suicide, what supports the study's findings previously presented. 
In these two studies, the authors discuss the importance of understanding the association between suicidal behaviours/thoughts and obesity in the context of a complex net of biological, psychological, social, and environmental factors.

Roberts et al. (2003) developed an interesting study using prospective data of the Alameda County Study (from the 1994 and 1999 surveys) to explore the possible associations between depression and obesity, namely if: (1) obesity increases the risk of depression; (2) depression increases the risk of obesity; (3) there is a reciprocal relation between depression and obesity; (4) and there is no association between depression and obesity. In this study they found evidence only for the first hypothesis i.e. obesity at baseline was associated with being depressed at follow-up 5 years later-, confirming the adverse effects of obesity on mental health.

A literature review conducted by McElroy et al. (2004) shows that obesity, overweight and abdominal obesity are recurrent problems in individuals seeking treatment for certain mood disorders, but also that mood disorders (in particular depressive disorder) are common in individuals seeking treatment for obesity. The authors also concluded that obesity and mood disorders share other similarities such as overeating, physical inactivity and weight gain; both conditions are associated with stigma; both respond to medications that selectively enhance central serotonin, norepinephrine, and/or dopamine function; and both respond better to combinations of psychological and pharmacological treatments than to either of these modalities alone.

Tuthill et al. (2006) studied depression and anxiety symptoms in individuals seeking treatment at specialist clinics in two United Kingdom centres and found that there is a high prevalence of psychiatric co-morbidities in individuals with obesity $(60.5 \%$ of women and $42 \%$ of men met the minimum criteria for an anxiety disorder; and $48 \%$ of both men and women met the minimum criteria for depression).

Studies focused in bariatric surgery candidates consistently show that current and past psychiatric disorders are more prevalent among these patients, and are associated with higher body mass index and poor functional health status (KALARCHIAN et al., 2007). According to the study conducted by Mühlhans, Horbach and Zwaan (2009) with bariatric surgery candidates who were at a very early stage of the process, mood disorders, particularly depressive disorders, were the most prevalent class of lifetime psychiatric disorders, and eating disorders were the most prevalent class of disorders at the time of the evaluation. Also Abilés et al. (2010) studied psychological characteristics of morbidly obese candidates for bariatric surgery and concluded that these patients reveal higher levels of stress, anxiety, depression, food craving and symptoms of eating behaviour disorder compared to normal-weight controls.
Psychopathology - namely depression, somatization, obsessive-compulsivity, interpersonal sensitivity, anxiety, hostility, phobic anxiety, paranoid ideas and psychoticismalso seems to be more frequent in women with obesity who seek for weight loss treatment and who additionally suffer from binge eating disorder than in those who do not present this eating disorder (FANDIÑO et al., 2010).

Nevertheless, the literature review on this subject suggests that when the population studied is constituted by individuals from the community who are overweight or have obesity, and not by those who are looking for weight-loss treatment, the majority of them do not present mood disorders (MCELROY et al., 2004).

Some studies have reported no relationship between depression and weight maintenance or even show contradictory findings, suggesting a positive association between initial depression and weight outcome loss after gastric bypass, as shown by the literature review conducted by Elfhag and Rössner (2005). For example, Legenbauer et al. (2011), studying the influence of depressive and eating disorders on short and long-term course of weight after surgical and nonsurgical weight loss treatment, concluded that depression and eating disorders were not associated with weight changes at the 1-year follow-up, even though 4 years after bariatric surgery, smaller body mass index loss was predicted by lifetime depression and depression at the baseline, and, curiously, lifetime diagnosis of eating disorder was associated with greater weight loss.

In spite of the interest revealed by researchers and clinicians in what concerns the role of mood, emotions, and emotional regulation in obesity, we still do not know the exact process by which emotions affect eating behaviour.

\section{Obesity and emotional regulation}

Research has been exploring, in early ages, an eventual relationship between emotion regulation and obesity. For example, Graziano, Galkins and Keane (2010) examined the role of early self-regulation skills in the development of pediatric obesity and verified that poor self-regulation skills in toddlerhood were predictive of being overweight in early childhood.

Evers, Stok and de Ridder (2010, p. 793) systematized distinct theories that have been developed in order to explain the association between emotions and food intake in three major perspectives:

(1) The eating behaviour is part of an attempt to escape from negative self-awareness, which means that the individual engage in binging episodes to avoid dealing with ego-threatening information;

(2) Overeating increases the experience of positive emotions, i.e. individual obtains pleasure from the qualities of the food ingested (e.g. taste, odour) or from the joy of eating "forbidden" food;

(3) Overeating is seen as an attempt to misattribute perceived stress to eating, in order to distract from the original source of stress. 
According to Evers, Stok and de Ridder (2010), the majority of these theories share the assumption that individuals overeat after experiencing negative affect that they cannot appropriately regulate. Thus, overeating is not necessarily related to the experience of negative emotions, but mostly to the lack of adaptive emotion regulation strategies, to the manner in which the emotion is dealt with.

Canetti, Bachar and Berry (2002) have also analyzed different theories which try to explain the association between emotions and eating behaviour, stressing the following ones:

(a) Psychosomatic theory, that presumes that individuals eat to reduce anxiety and discomfort;

(b) The internal/external theory, that assumes that overweight individuals do not recognize physiological hunger or satiety cues' because of a default in learning;

(c) The restraint hypothesis, that proposes that individuals who persistently restraint their food intake overeat in the presence of stress.

The fact that, despite the recognition of the importance of affective processes in eating behaviour, we still know very little about how they predict eating, lead Macht (2008) to conduct an extensive literature review, in the attempt of constructing an explanatory model. In that review it is possible to identify distinct ways in which emotions can affect eating along the entire process of ingestion: motivation to eat, affective responses to food, food choices, chewing, eating speed, amount ingested, metabolism and digestion. Moreover, this research review shows that emotions and mood can increase or decrease eating in distinct groups of individuals (for example, restrained eaters and unrestrained eaters), but this variability can also occur in the same group and in reaction to distinct positive and negative emotions.

Christensen (1993) has carried out a literature review on the effects of eating behaviour on mood and concluded that research shows paradoxical results. In spite of the fact that some studies shows that individuals experiencing a negative mood state make use of carbohydrate ingestion (particularly of simple carbohydrates) to provide a temporary lifting of mood, other studies show that some individuals may obtain a more permanent control of their negative mood state by eliminating simple carbohydrates from their diet.

During long time research studied the relationship between eating behaviour and emotions, but little attention was given to the differential effects of different emotions.

For example, Geliebter and Aversa (2003) found that overweight individuals, when experiencing negative emotional states or situations, eat more than normal-weight and underweight individuals, but they also found that the opposite occurs for positive emotional states or situations, with the underweight individuals reporting eating more than the other two groups.
Macht (2008) conducted a literature review on those effects and concluded that, on one hand, negative emotions (e.g. anger, fear, sadness) increase impulsive eating, eating to regulate the emotional state and consumption of junk food, although it decreases food pleasantness and, on the other hand, positive emotions (e.g. joy) increase food pleasantness and consumption of healthy foods. In addition, according to Macht, several of the studies reviewed reinforce the idea that most people report changes on eating (eat more or eat less) in response to emotional stress, as well as that negative emotional states in daily life can be associated with a tendency to eat as an emotion regulation strategy not only in restrained eaters and binge eaters, but also in normal eaters.

Zeeck et al. (2011) developed a study in which they explored the relationship between emotional experiences and eating. Their results suggest that anxiety has a minor importance in the context of eating when compared to other emotions, especially emotions related to interactions with others (e.g. being lonely, bored, hurt and disappointed). Furthermore, they concluded that individuals with binge eating cope with negative emotions (emotional stressors) by being more attracted to food and experiencing an increased desire to eat. These results are consistent with the theory of emotional eating, which defends that some individuals use eating as a strategy to regulate negative emotions.

There has been some efforts to develop assessment instruments that allow a carefully measure of emotional regulation through eating. For example, Ozier et al. (2007) developed and validated the Eating and Appraisal Due to Emotions and Stress (EADES) Questionnaire, instrument which construction was based on the Eating and Appraisal Due to Emotions and Stress Model and that aims to measure how the individuals use food to cope with stress and emotions. This model was conceived by these authors inspired in the Lazarus and Folkman's Transactional Model of Stress and Coping, that they believed to provide a framework for evaluating the process of coping with stress and emotions and to help explaining the differences in the way stress affects different people.

Ozier et al. (2008) empirically tested EADES Questionnaire intending to identify if the constructs from the theoretical model adopted were, in fact, related to overweight and obesity. They verified that there was an association between the "emotion and stress-related eating" factor and the likelihood of being overweight or obese, but not between the "appraisal of outside influences/ stressors" factor and overweight or obesity, what lead them to conclude that this assessment tool can be used to assess non-traditional factors that contribute to overweight and obesity, though further studies about it are needed.

Research has also been exploring the importance of alexithymia (a multifaceted construct that involves difficulty in identifying subjective emotional feelings, the ability to distinguish between feelings and bodily sensations, and difficulty in describing feelings to other people) in obese patients emotional eating. Larsen et al. 
(2006) analyzed this issue and verified that alexithymia is more strongly involved in emotional eating of men with obesity than in women with this disease and concluded that this suggests that the design of treatments for emotional eating among individuals with obesity should take in account these gender differences.

Pinaquy et al. (2003) have also investigated the relationship between alexithymia and emotional eating in obese women with and without binge eating disorder and verified that women reporting binge eating disorder presented higher depression, anxiety, perceived stress, alexithymia, and emotional and external eating than those who did not reported this eating disorder. Furthermore, they concluded that the relationship between alexithymia and emotional eating differed between these two groups of women - while alexithymia was a predictor of emotional eating in women with binge eating disorder, perceived stress and depression were predictors of emotional eating in women without this eating disorder.

More recently, Zijlstra et al. (2012) compared emotion processing and regulation between women with morbid obesity candidates to bariatric surgery and women from general population, and verified that the first group reported higher scores on difficulty to identifying emotions (alexithymia) and suppression of emotions than de second one. Additionally, in women with morbid obesity, higher negative affect and higher difficulty identifying feelings were correlated with more emotional eating. The authors concluded that negative emotions and unhealthy emotion processing may play a role in emotional eating, possibly contributing to initiate or perpetuate mechanisms in morbid obesity.

The vast diversity of individual results in obesity treatment, lead researchers to analyze psychosocial pre-treatment predictors of weight control. Teixeira et al. (2005) conducted a literature review which suggests that treatment outcomes are not predicted by some variables assessed before treatment, namely binge eating, eating disinhibition, restrain and depression. They also concluded that research is inconsistent in what concerns to a considerable number of psychosocial constructs, as self-efficacy, body image, self-esteem, outcome expectancies, weight-specific quality of life.

On the contrary, the investigation on the long-term success of distinct treatment programmes - Cognitive-Behavioural Treatment and Behavioural WeightLoss-Treatment - for overweight and obese patients who suffer from binge eating disorder revealed that the major predictor of success is rapid response, that is a strong decrease of symptoms during the first four therapy sessions, suggesting that strategies as homework assignment and self-monitoring contribute to improve self-efficacy and decrease depression which can constitute a key ingredient in treatment planning (MUNSCH; MEYER; BIEDERT, 2012).

Fractal, Rev. Psicol., v. 27 - n. 3, p. 286-290, 2015

\section{Discussion}

Thus, emotional regulation does seem to play an important role in eating behaviour and weight management. We need theory-based formulations in behavioural loss research that deepen our understanding about these processes, but, as Teixeira et al. (2005) recognize, we cannot forget that it is remarkably difficult to produce a single theoretical representation predictive of an outcome as complex as human weight change over time. Moreover, a large number of studies have been conducted in this field, but there is a huge variability in the methodologies adopted, which can make even more difficult the effort in order to develop those formulations.

If psychiatric disorders, depression and anxiety symptoms are cause or consequence of obesity remains an open question. Emotion regulation has been pointed as having an important role in eating behaviour and weight management, but new efforts concerning theory development are needed, as well as to systematically replicate findings across studies.

There is also a wide gap concerning cultural, ethnic and cross-country differences in this filed. Therefore, research conducted by international cross-disciplinary teams should be encouraged.

In conclusion, there have been several efforts to deepen the knowledge about the role of mood, emotions and emotional regulation in obesity and weight loss treatment outcomes, but more than answers, studies have been revealing new research paths to follow in the understanding of such a complex field.

\section{References}

ABILÉS, V. et al. Psychological characteristics of morbidly obese candidates for bariatric surgery. Obesity Surgery, v. 20, n. 2, p. 161-167, 2010.

BECKER, E. S. et al. Obesity and mental illness in a representative sample of young women. International Journal of Obesity and Related Metabolic Disorders, v. 25, supl. 1, p. S5-9, 2001.

CANETTI, L.; BACHAR; E.; BERRY, E.M. Food and emotion. Behavioural Processes, v. 60, n. 2, p. 157-164, 2002.

CHRISTENSEN, L. Effects of eating behavior on mood: a review of the literature. International Journal of Eating Disorders, v. 14, n. 2, p. 171-183, 1993.

ELFHAG, K.; RÖSSNER, S. Who succeeds in maintaining weight loss? A conceptual review of factors associated with weight loss maintenance and weight regain. Obesity Reviews, v. 6, n. 1, p. $67-85,2005$.

EVERS, C.; STOK F. M.; DE RIDDER, D. T. D. Feeding your feelings: Emotion regulation strategies and emotional eating. Personality and Social Psychology Bulletin, v. 36, n. 6, p. 792804, 2010

FANDIÑO, J. et al. Impact of binge eating disorder in the psychopathological profile of obese women. Comprehensive Psychiatry, v. 51, n. 2, p. 110-114, 2010.

GELIEBTER, A.; AVERSA, A. Emotional eating in overweight, normal weight, and underweight individuals. Eating Behaviors, v. 3, n. 4, p. 341-347, 2003. 
GRAZIANO, P. A.; GALKINS, S. D.; KEANE, S. P. Toddler self-regulation skills predict risk for pediatric obesity. International Journal of Obesity, v. 34, n. 4, p. 633-641, 2010.

KALARCHIAN, M. A. et al. Psychiatric disorders among bariatric surgery candidates: relationship to obesity and functional health status. American Journal of Psychiatry, v. 164, n. 2, p. 328-334, 2007.

KARK, M.; NEOVIUS, M.; RASMUSSEN, F. Obesity status and risk of disability pension due to psychiatric disorders. International Journal of Obesity, v. 34, n. 4, p. 726-732, 2010.

KLINITZKE, G. et al. Obesity and suicide risk in adults: a systematic review. Journal of Affective Disorders, v. 145, n.3, p. 277-284, 2013.

LARSEN, J. K. et al. Gender differences in the association between alexithymia and emotional eating in obese individuals. Journal of Psychosomatic Research, v. 60, n. 3, p. 237-243, 2006.

LEGENBAUER, T. et al. Influence of depressive and eating disorders on short- and long-term course of weight after surgical and nonsurgical weight loss treatment. Comprehensive Psychiatry, v. 52, n.3, p. 301-311, 2011.

MACHT, M. How emotions affect eating: a five-way model. Appetite, v. 50, n.1, p. 1-11, 2008.

MCELROY, S. L. et al. Are mood disorders and obesity related? A review for the mental health professional. Journal of Clinical Psychiatry, v. 65, n. 5, p. 634-651, 2004.

MERWE, M.-T. Psychological correlates of obesity in women. International Journal of Obesity, v. 31, supl. 2, p. 514-518, 2007.

MÜHLHANS, B.; HORBACH, T.; ZWAAN, M. Psychiatric disorders in bariatric surgery candidates: a review of the literature and results of a German prebariatric surgery sample. General Hospital Psychiatry, v. 31, n. 5, p. 414-421, 2009.

MUNSCH, S.; MEYER, A. H.; BIEDERT, E. Efficacy and predictors of long-term treatment success for cognitivebehavioral treatment and behavioral weight-loss-treatment $n$ overweight individuals with binge eating disorder. Behaviour Research and Therapy, v. 50, n. 12, p. 775-785, 2012.

OZIER, A. D. et al. The Eating and Appraisal Due to Emotions and Stress (EADES) Questionnaire: Development and validation. Journal of the American Dietetic Association, v. 107, n. 4, p. 619-628, 2007.

OZIER, A. D. et al. Overweight and obesity are associated with emotion- and stress-related eating as measured by the Eating and Appraisal Due to Emotions and Stress Questionnaire. Journal of the American Dietetic Association, v. 108, n. 1, p. 49-56, 2008.

PINAQUY, S. et al. Emotional eating, alexithymia, and bingeeating disorder in obese women. Obesity Research, v. 11, n. 2, p. 195-201, 2003.

ROBERTS, R. E. et al. Prospective association between obesity and depression: evidence from the Alameda County Study. International Journal of Obesity, v. 27, n. 4, p. 514-521, 2003.

SIMON, G. E. et al. Association Between Obesity and Psychiatric Disorders in the US Adult Population. Archives of General Psychiatry, v. 63, n. 7, p. 824-830, 2006.

TEIXEIRA, P. J. et al. A review of psychological pre-treatment predictors of weight control. Obesity Reviews, v. 6, n.1, p. 43-
$65,2005$.

TUTHILL, A. et al. Psychiatric comorbidities in patients attending specialist obesity services in the UK. The Quarterly Journal of Medicine, v. 99, p. 317-325, 2006.

ZHANG, J.; LI, F.; MCKEOWN, R. E. Body mass index and suicidal behaviours: a critical review of epidemiological evidence. Journal of Affective Disorders, v. 148, n. 2-3, p. 147$160,2013$.

ZEECK, A. et al. Emotion and eating in binge eating disorder and obesity. European Eating Disorders Review, v. 19, n. 5, p. 426-437, 2011.

ZIJLSTRA, H. et al. Emotion processing and regulation in women with morbid obesity who apply for bariatric surgery. Psychology \& Health, v. 27, n. 12, p. 1375-1387, 2012.

Received: April 25, 2015 Accepted: September 24, 2015 